\title{
Compatibility of the SAFE FOODS Risk Analysis Framework with the legal and institutional settings of the EU and the WTO
}

\author{
Ariane König * \\ Conseillère du Recteur et Responsable Pour le Développement Durable, Université du Luxembourg, 162A Avenue de la Fä̈encerie, L-1511 Luxembourg, Luxembourg \\ Institute for Science, Innovation and Society, Saïd Business School, University of Oxford, Park End Street, Oxford OX1 1HP, UK
}

\section{A R T I C L E I N F O}

\section{Article history:}

Received 1 October 2008

Received in revised form 25 August 2009

Accepted 25 November 2009

\section{Keywords:}

European Union food law

World Trade Organisation

Codex Alimentarius Commission

Risk analysis

Food safety

\begin{abstract}
A B S T R A C T
This paper analyses the compatibility of the SAFE FOODS recommendations with the food safety governance systems of the EU and the World Trade Organisation (WTO), in which standard setting procedures of the Codex Alimentarius Commission (CAC) are considered most relevant. The objective is to better understand the implications from (1) the addition of formalised framing and evaluation stages to the risk analysis process and (2) the expansion of the scope of the risk assessment to comprise the distribution of risks, benefits and costs of regulatory measures. The paper concludes that these recommendations of the SAFE FOODS project are compatible to EU law provided they are fine-tuned to legal provisions on specific roles for agencies, EU Member States and the European Commission services. All recommendations are deemed largely compatible with the rules for procedure of the CAC.
\end{abstract}

(C) 2009 Elsevier Ltd. All rights reserved.

\section{Introduction}

The main lessons from the Bovine Spongiform Encephalopathy (BSE) and other food safety crises in the 1990s include that governance in situations of high systems uncertainty, ${ }^{1}$ high stakes, and value loading, requires input from multiple legitimate perspectives (see for example Dreyer \& Renn, 2006; Funtowicz \& Ravetz, 1992, 1993; Gottweis, 2008; Jasanoff, 1997; Ravetz, 1999). Accordingly, many governments in the European Union (EU) and elsewhere are devising and trialing new approaches to make processes for risk governance more inclusive of public concerns.

Abbreviations: BSE, bovine spongiform encephalopathy; CAC, Codex Alimentarius Commission; CFI, European Court of First Instance; DG, Directorate General; DG SANCO, European Commission Directorate General for Health and Consumers; EC, European Community; EFSA, European Food Safety Authority; EU, European Union; FAO, Food and Agriculture Organisation; GMO, genetically modified organism; JECFA, Joint Expert Committee for Food Additives; JMPR, Joint Meeting on Pesticide Residues; NUSAP, Numeral Unit Spread Assessment Pedigree; QALY, qualityadjusted life years; SCAN, Scientific Committee on Animal Nutrition; SPS Agreement, Agreement on the Application of Sanitary and Phytosanitary Measures; UK, United Kingdom; US, United States; WHO, World Health Organisation; WTO, World Trade Organisation.

* Address: Conseillère du Recteur et Responsable Pour le Développement Durable, Université du Luxembourg, 162A Avenue de la Faïencerie, L-1511 Luxembourg, Luxembourg. Tel.: +352 4666446233.

E-mail address: ariane.koenig@uni.lu.

${ }^{1}$ In this line of thought, systems can comprise natural systems like organisms or eco-systems, social systems, and their interactions.
The SAFE FOODS project has developed a set of recommendations to make risk analysis procedures more inclusive, open, accountable and reflexive (see König et al., this issue). A second and related goal is to shift the focus in food safety governance from reducing risks to improving public health. The suggested improvements to current food safety governance systems are intended to be incremental in nature such that can be adopted relatively easily, avoiding for example the need for major changes in the current EU legal and institutional setting. ${ }^{2}$ This paper analyses whether the unique features of the SAFE FOODS Risk Analysis Framework are indeed compatible with current food safety governance systems of the EU and the World Trade Organisation (WTO).

The analysis presented in this paper draws on research conducted throughout the development of the SAFE FOODS framework (for an overview on methods for development of the SAFE FOODS framework, see Cope, Frewer, Renn, \& Dreyer, this issue). Work of the SAFE FOODs project also involved a comparative study of changes in food safety governance in several Member States in response to the recent series of food crises, focussing on the interface between risk assessment and risk management (Dreyer et al., 2008; Vos \& Wendler, 2006). Most fundamental to the analysis presented in this paper were the legal and policy analysis to identify gaps between principles for good governance and practice (see also König, 2007a, 2007b; König et al., this issue), stakeholder

\footnotetext{
${ }^{2}$ A food safety system is conceived as comprising institutions, policies and the legal framework for the risk analysis of foods, and current practice in implementation.
} 
workshops with the objective of collecting feedback on preliminary SAFE FOODS recommendations from practitioners involved in food safety systems SAFE FOODS, 2005, 2007), and results from a Delphi survey (Wentholt, Rowe, König, Marvin, \& Frewer, 2009).

For the purpose of the legal analysis, this paper distinguishes three levels in the regulatory architecture of food safety governance systems: (i) general principles of treaties and policies for good governance, (ii) food law and rules for procedure, and (iii) current practice for implementation by a closely collaborating network of administrative bodies, experts, and stakeholders in the EU. After providing a brief overview on the unique features of the SAFE FOODS system, this paper considers the compatibility of SAFE FOODS recommendations with the EU food safety governance system at each of these levels in turn. Subsequently, the paper considers implications of the adoption of these recommendations for judicial review. Last, the SAFE FOODS framework and the EU system are compared to the main provisions for food safety governance under the current WTO trade regime, where rules of procedure of the Codex Alimentarius Commission (CAC) are considered most relevant.

The overall conclusions point out areas for future research on improving the transparency and accountability of the EU and global food safety systems. Furthermore, the conclusions provide some suggestions on requisites for improving food safety governance systems that would be of less incremental nature than changes advocated in the SAFE FOODS project, with a view to make food safety governance more compatible with goals of sustainable development.

\section{Main features of the risk analysis of foods and the SAFE FOODS framework}

The most current conception of the risk analysis process distinguishes three main activities: risk assessment, risk management and risk communication (see also Alemanno, 2007a, 2007b; König, 2007a, 2007b; Renn, 2007; Vos \& Wendler, 2006). Risk assessment is "the determination of the likelihood of the occurrence and potential magnitude of harm." Risk management is "the process of weighing, selecting and implementing policy alternatives in the light of risk assessment"; and risk communication is the interactive exchange of information between risk assessors, managers, interested and affected parties, and the public (FAO/WHO, 1995, 1997). Risk analysis processes should be iterative, that is, provide for opportunities to review as knowledge and social norms relating to the issue evolve (National Research Council, 1994). This framework is also endorsed by the CAC that sets official standards and guidelines recognised by the WTO's Appelate Body. ${ }^{3}$ Most countries therefore have adopted similar general provisions. The definitions of these concepts in the general framework regulation ${ }^{4}$ for EU food law (EU, 2002) and the CAC carry largely the same in meanings. ${ }^{5}$

The main objective in the development of the SAFE FOODS framework for risk analysis of foods was to improve transparency, openness and accountability of current procedures (König et al., this issue), describes the SAFE FOODS framework in much greater detail. See also, Dreyer et al., 2008; Dreyer \& Renn, 2006). Accordingly, the SAFE FOODS framework is constituted of five stages: framing, risk-benefit assessment, evaluation, risk management including monitoring, review and re-framing, and risk communica-

\footnotetext{
${ }^{3}$ The World Trade Organisation's Final Act included the "Agreement on the Application of Sanitary and Phytosanitary Measures" and referred to the Agreement on Technical Barriers to Trade.

${ }^{4}$ Regulation (EC) No. 178/2002 establishing the general principles and requirements of food law, establishing the European Food Safety Authority and laying down procedures in matters of food safety.

5 The slight differences between them are further discussed in section 8 below.
}

tion (see Fig. 1). It thus adds two main new formalised activities framing and evaluation to the three commonly institutionalised risk analysis activities. The other key distinction of the SAFE FOODS Risk Analysis Framework is the option to expand the scope of the assessment to include not only risks and benefits to human health, but also a comparison of the distribution of risks, costs and benefits associated with alternative courses of regulatory action. In contrast to these recommendations, current practice is largely focused on assessing the likelihood and severity of adverse health impacts based on point estimates of health impacts and exposures. This section focuses on describing main rationales for introducing the three new elements framing, expanded assessment scope and evaluation.

Framing: serves for the formal documentation of areas of consensus and dissent on the issue from diverse legitimate perspectives. Central to the framing process are questions on the objectives of food safety governance and new technologies at issue, associated distributions of benefits, risks and costs, and how and what we may learn from their adoption (Jasanoff, 2003; Wynne, 2003). One main rationale supporting a formal framing step is that prevailing social norms that would guide judgment on an issue in communities of expert scientist may differ from those of citizens who were not trained in approaching the subject matter in a similar manner. Accordingly, expert scientists may not ask those questions that may be of most import to other members of society, such that advice lacks social and political salience (Funtowicz \& Ravetz, 1992; König \& Jasanoff, 2002; Wynne, 1985, 1996). Diverse view points from experts, managers and interested parties for the construction of the 'frame' for the issue can be gathered by systematically reviewing available information in the public domain and/or by relying on methods for consultation, or direct participation (see for example Kasemir, Jäger, Jaeger, \& Gardner, 2003; Wardecker et al., 2009). Insights gained in the framing process then can inform the definition of the terms of reference for the assessment - what questions should be addressed, based on what expertise and data.

Expanding the scope of the assessment: the main difference between the assessment stage in the SAFE FOODS Framework and the status quo at EU-level is the distinction between two main types of assessment: the largely natural science-based risk-benefit assessment of health and environmental impacts, and the assessment of economic impacts (Traill \& König, this issue), social impacts (Dreyer, Renn, Cope, \& Frewer, this issue) and ethical aspects. For decisions on food safety the health impact assessment remains of primary importance (see König et al., this issue, and for an overview on health risk assessment, see Smith, 2002).

The project also developed concrete recommendations on how to use latest scientific developments on the forefront in the areas of systems biology (Davies, this issue) and probabilistic modelling of health impacts in risk assessment (Boon et al., 2009; Bos et al., 2009; Bosgra, van der Voet, Boon, \& Slob, 2009; Muri, van der Voet, Boon, van Klaveren, \& Brüschweiler, 2009; Müller et al., 2009; Van der Voet \& Slob, 2007; Van der Voet et al., 2009) in order to better tailor the assessment to the issue at stake. Some of the tools proposed for wider adoption in practice of risk assessment at EU-level also help improved characterisation and communication of uncertainties, in response to critique that there is definite room for improvement of describing uncertainties in particular from risk assessors to risk managers. Today EU institutions use primarily point estimates - or the deterministic approach.

The SAFE FOODS recommendation of greater use of probabilistic analyses for better characterizing uncertainty and variability in risk is fully compatible with current practice. Monte Carlo techniques for probabilistic modelling are emerging as the preferred method for error propagation in risk analysis and have now widely been adopted in the United States (US). The method can also be used to determine relative contributions of uncertainty and vari- 


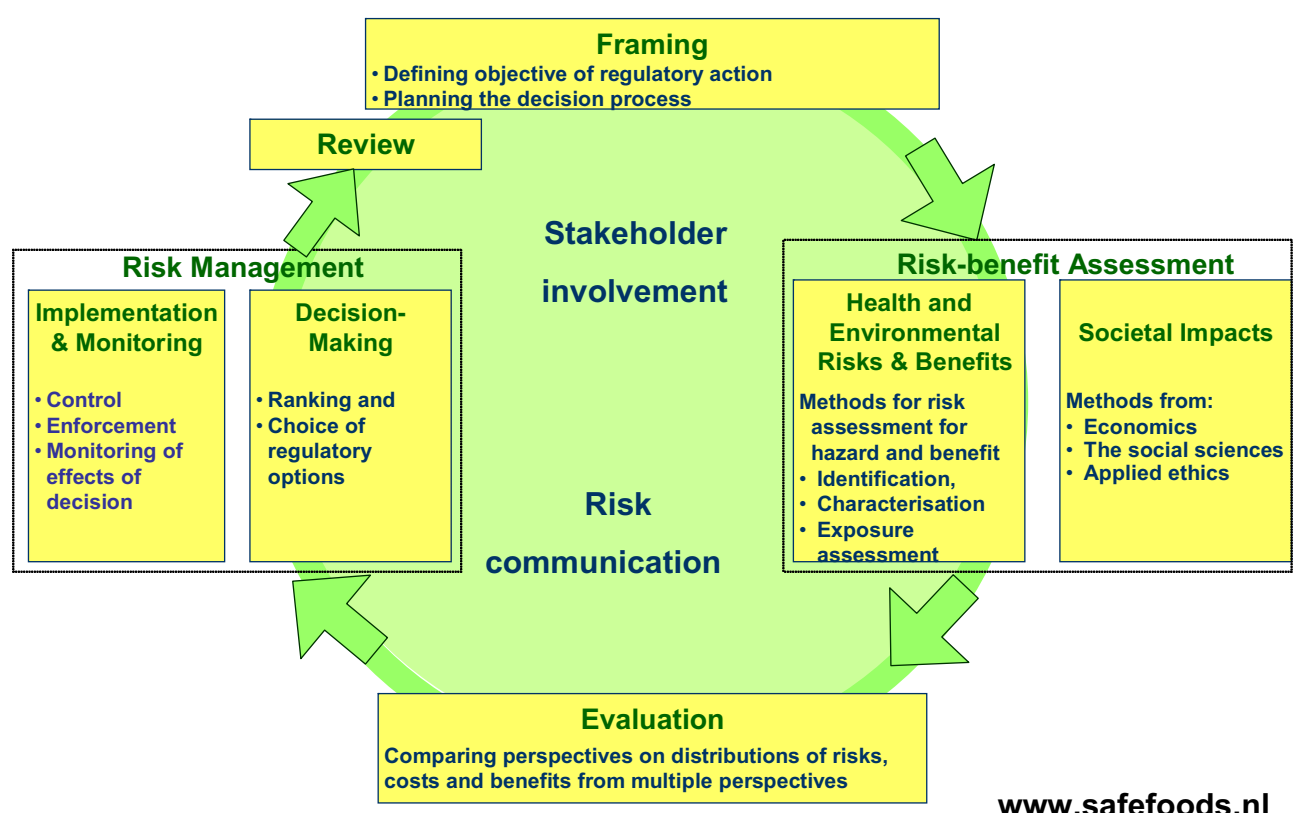

Fig. 1. The SAFE FOODS framework for the risk analysis of foods.

ance into the overall variance of risk. Two-dimensional Monte Carlo models exist for maintaining the distinction between uncertainty and variability. These methods are however only applicable provided sufficient quality data exists on dose-response relationships and distribution of differential vulnerabilities for the issue at hand.

More generally applicable, the Numeral Unit Spread Assessment Pedigree (NUSAP) method $^{6}$ that was developed to better characterise and communicate about uncertainties is one useful tool for this stage (Funtowicz \& Ravetz, 1990), and is compatible with current practice, laws, and institutional set-ups. This tool is not only suitable for improving communication on uncertainties between risk assessors and risk managers, but also for use in the evaluation stage to assess the significance of uncertainty as viewed from en extended peer community.

The evaluation stage provides an opportunity to assess the quality of policy proposals by combining multiple perspectives on the issue, mainly to probe the significance of uncertainties and value loading of claims (Funtowicz \& Ravetz, 1992, 1993; Ravetz, 1999). Here, interested parties, experts and officials can use the assessment outcome to compare the relevant risks, costs, and benefits and their distribution. Such 'quality assessment' processes require debates inclusive of a variety of perspectives and information sources (for approaches to staging such debates see, for example, Kasemir et al., 2003; Wardecker et al., 2009). Therefore, electronic consultation tools not allowing for joint deliberation may not always prove adequate.

In sum, the exact procedural nature of the framing and evaluation stages, and associated resource requirements will depend on the issue at hand. It is, however, deemed advantageous if those who participate in framing also engage at the evaluation stage. Such continuity would help participants gaining familiarity with

\footnotetext{
${ }^{6}$ Described are the Number itself, Unit Spread, Assessment and Pedigree; accordingly, the approach is called the NUSAP approach. The assessment serves to describe views on why this figure may be significant, optimistic or pessimistic. Pedigree is a criterion that unites aspects on how this number was produced, looking at underlying definitions and standards, data collection and analysis, institutional culture (degree of openness during production), and review (Funtowicz \& Ravetz, 1990).
}

the issue and the other view points (Dreyer et al., 2008). As analysed in more detail below, the main difference to current practice is the formal organisation and documentation of such stages that then leaves a paper trail to make considerations underlying the formulation of the terms of reference for the assessors and the final decision much more transparent. All suggestions on framing and evaluation are compatible with the current legal and institutional context. Added reflexivity is gained by involving critical minds for the system to learn from feedback from extended peer communities which will benefit review and future risk analysis cycles. However, whilst advocated in EU principles on better regulation, expanding the scope of the assessment in the context of the EU food safety governance system poses some legal and institutional challenges. The type of data that can be considered and the type of expert advice that can be given by specific advisory committees (be they experts on risk assessment, or on the food chain) is often further specified in secondary, or implementing legislation on specific foodstuffs.

Depending on the specific laws and on established precedents, the determination of the significance of a risk by a risk manager is either solely based on how a particular risk compares to other risks, or on the costs and benefits of alternative courses of regulatory action (Thompson \& Graham, 1996). The leading US economist Ken Arrow argued that laws preventing the consideration of costs in selecting alternative regulatory measures do not guarantee to contribute to the public good (Arrow et al., 1996). One reason is that as in any situation of imperfect knowledge, risk managers have to use judgments to complement existing scientific data. Given scarce government resources for public health, choice of any regulatory measure will, to some extent, be based on consideration of cost of alternatives. A second reason is transparency. What is really being considered? Bias to documenting natural science considerations on point estimates of risks may leave out issues that are of real concern, leading to solutions that may be irrelevant (National Research Council, 1994). The social, cultural, and institutional context contributes to shaping our understanding of risk and associated uncertainties (Jasanoff, 1987). These legal challenges and solutions that obviate changes in the law are discussed in further detail in subsequent sections of the paper below. 


\section{General principles in treaties and policies on governance in the EU}

Procedures for risk analysis of foods that aim to engage experts, affected parties, and risk managers should as far as possible be conform with general principles in the Treaty on the European Union on the delegation of powers and implementing laws on EU comitology, as well as to principles and policies on good governance. This highest level of the regulatory architecture of EU food safety governance can contain binding provisions affecting the distribution of power between Member States, the European institutions, experts, and agencies (Rudloff \& Simons, 2007). Although the SAFE FOODS objectives fit well with today's challenging policy and legal requirements on transparency, openness, participation, and improved accountability, there can be tensions between these and other legal requirements for the distribution of powers at EU-level, such as the separation of risk assessment and management and principles on the proportionality, consistency, and non-discrimination of decisions. Accordingly, this section discusses such tensions, focusing first on the Treaty provisions on the delegation of powers, and second on policies on good governance of the European Commission published since 2000 .

\subsection{Legal principles on the delegation of powers in the EU}

The formal delegation of authority to non-democratically appointed bodies is one of the major challenges to democratic governance (Guston, 2000). Often in food safety governance these acts of delegation follow a formal set of principles of treaties or constitutions providing an overarching procedural framework for sectoral regulations. Delegation in a multi-level governance system such as the EU, with complex rules on sharing sovereignty between Member States and the European Institutions, is particularly challenging (Hofmann \& Tuerk, 2006).

Since the ratification of the 1957 Treaty of Rome establishing the European Economic Community, the remit of the EU has expanded from a purely economic focus to encompass increasingly political realms. The legal basis for EU public health policy was only granted later with the Single European Act of July 1987, which added powers to the Treaty providing for the European institutions, competence in matters of environment and health and safety at work. Since the Treaty of Amsterdam came into force in May 1999, policy and legislative activities on matters regarding the environment and public health are decided in accordance with the co-decision procedure of Article 251 of the Treaty. ${ }^{7}$ According to the principle of subsidiarity, the European Commission's role is, in theory, to act as a "neutral" broker by administering the consensus-finding or voting processes of Member State regulatory committees. The regulatory committees usually vote on the proposals of the European Commission. These processes are governed by the Comi-

\footnotetext{
7 Under this decision-making procedure, Parliament can propose amendments to the law. The Parliament has two readings to amend the draft legislation proposed by the Commission. The Council brings forward a common position of the Member States that is based on the Commission initiative and Parliament's proposed amendments Support from a qualified majority of Member States is required to adopt Parliament's amendments that have been accepted by the European Commission and to pass the law. This decision-making process involves close cooperation of Member State representatives in the Council, members of Parliament, and officials of the European Commission (For a thorough explanation of the legislative processes in the EU see Craig \& De Burca, 2003). The Economic and Social Committee has to be consulted. In the European Commission, the Directorate General (DG) for Consumer Protection and Public Health (which was recently renamed and is now called DG for Health and Consumers), the Directorate General for Research, the Joint Research Centres, and the Directorate General for Enterprise are most closely involved with food safety policy and legislation. Each have instituted advisory structures for officials to solicit in-depth knowledge from those involved in the practice or from those who have other types of expertise in the area of food safety and production.
}

tology rules concerning EU Committees. Principles that would have the potential to enhance the conditions for democracy in the realm of comitology have been proposed by others (Toeller \& Hofmann, 2000). SAFE FOODS has focused on enhancing conditions for democracy in the development of the proposals from the European Commission, for the preparation of which officials usually solicit expert advice.

The distribution of powers between the Council of Ministers, the European Commission and expert committees were clarified by a ruling of the European Court of First Instance (CFI) on the use of antibiotics in animal feed. Here, the CFI concluded that the European Commission and the Council may disregard conclusions drawn from expert opinion, as members of expert committees have "neither democratic legitimacy nor political responsibilities", whereas the European Commission's authority "is rendered legitimate and democratically accountable" pursuant to Article 211 of the European Community (EC) Treaty, and by the European Parliament's political control. ${ }^{8}$ The European Commission policy documents on agencies and expertise further emphasise that its experts "cannot be granted decision-making power in areas where they have to arbitrate between conflicting public interests, exercise political discretion, or carry out complex economic assessments" (European Commission, 2002b).

The EU Treaty provisions on division of powers are hence compatible with the recommendations of the SAFE FOODS Risk Analysis Framework to stage framing and evaluation processes that involve participation of affected parties and experts, provided it is assured that European Commission officials are responsible for summarising and using the results from the framing and evaluation step. Composite bodies engaging diverse interests cannot have decision powers, but they can have advisory functions. The principles of delegation in addition to shaping possible roles for experts, officials, and affected parties, also some what limit the tasks of experts, as experts for example should not "carry out complex economic assessments" or have a say over the distribution of costs and benefits. Care has therefore to be taken in SAFE FOODS recommendations on who carries out social and economic impact assessments.

That means, if experts and affected parties are involved as well as risk managers, outputs from the group can be considered as advice towards defining terms of assessment and decision-making. How this advice is used lies at the discretion of the European Commission officials drafting the terms of reference or proposal for a decision that is usually to be voted upon by a regulatory committee of Member States.

Although some critics may bemoan that how diverse view points come to bear on the process will be filtered through the European Commission's perspective, the participation of diverse legitimate perspectives in framing and evaluation stages clearly creates greater accountability of the officials in charge of the risk analysis process to all those who have participated in it. A second layer of public accountability could be created by making documentation on the framing and evaluation stages publicly available. That officials should stay responsible is democratically correct from the view point that all decisions on process have resource implications for public funds, and only those with authority to manage these funds should take decisions affecting their use.

\footnotetext{
${ }^{8}$ European Court of Justice, T-13/99, Pfizer ECR II-3305, at paras. 200-201. This judgment related to a case where the European Commission asked advice from the Scientific Committee on Animal Nutrition (SCAN) on the use of antibiotics as growth promoters. Although SCAN did not consider the use of Virginiamycin for the stated purpose an immediate risk to public health, the Commission and the Council decided to revoke the authorisation on grounds of remaining uncertainties. The court upheld the Council's decision.
} 


\subsection{Principles and policies on good governance}

Whilst, in line with principles on the delegation of powers, principles and policies on good governance support the separation of risk assessment and risk management, they also clearly support creating greater accountability between risk assessors and managers, opening governance processes and more routine conduct of formal and transparent assessments of social and economic implications.

The separation of risk assessment and management: the policy on the strict separation of assessment and management at EU-level was in large part triggered by the food safety crises in the 1990s, including the BSE crisis (see also Renn, 2007). Until 1997, scientific advisory bodies to the European Commission were usually administered by the Directorates General responsible for administering the respective legislative sectors. In 1997, at the peak of the BSE crisis, the then President of the European Commission, Jacques Santer, in a speech to the European Parliament, announced general principles for the management of food safety and consumer health. Among the proposed principles were that responsibility for legislation should be separate from that for scientific consultation, and that there should be greater transparency and more widely available information throughout the decision-making and inspection process. All scientific committees were moved from the Directorates with the respective legislative responsibilities to the then newly created Directorate General for Consumer Protection in order to separate legislative and policy responsibility from that for scientific consultation. The subsequent European Commission Communication on Consumer Health and Safety announced these changes and, as indicated by the following statement, placed emphasis on the excellence of the committee members and the independence and transparency of the advice: "Consumer confidence in the legislative activities of the EU is conditioned by the quality and transparency of the scientific advice and its use on the legislative and control process" (European Commission, 1997a).

Accordingly, the SAFE FOODS Risk Analysis Framework foresees separate risk assessment and risk management stages. In order to ensure an improved connection and greater mutual accountability between risk assessors and risk managers and affected parties, the framework foresees two additional stages, framing and evaluation. These additional stages serve to open up risk analysis processes and assure that assessors and managers formally interact to work towards shared definitions of problems and scope of knowledge requirements for supporting decisions, and better understand and become more accountable to other legitimate perspectives of affected parties.

Framing and evaluation: since the Treaty of Amsterdam, Article 1 of the Treaty of the European Union establishes as a general principle that decisions are to be taken as openly as possible and "as closely as possible to the citizen," a whole host of secondary legislation to implement this Treaty provision have been adopted and continue to be negotiated. Many of these provisions are intended to enhance the transparency, inclusiveness, and public accountability of policy processes, and clarify who should partake how, and what should be considered.

Early examples of related implementing provisions of such general principles on good governance relating to the opening of policy processes in the field of environmental policy include the 1997 Commission Decision on Public Access to Documents of the European Environment Agency and the 1997 Council Resolution on Drafting, Implementing and Enforcing Community Environmental Law. The latter, apart from highlighting the need for transparency, also recommends increased participation in the form of stakeholder consultation "at an early stage on concrete legislative proposals." Similarly, the conclusions of the March 2000 Lisbon
European Council stressed that the European Institutions, national governments, and regional and local authorities should pursue their dialogue with business and citizens, in particular in the context of impact and compliance costs of proposed legislation. The Directive on Public Access to Documents handled by the European institutions provides citizens with the right to access official papers under EU law, unless officials can prove that their release would be harmful (EU, 2001).

The 2001 White Paper on Governance, a priority of the Prodi Commission, forms the basis for the so-called "Better Regulation Package" that sets the goal of simplifying legislation and making the system more accountable. In 2002, Romano Prodi attempted to bring EU institutions closer to the citizenry, and published a set of nine communications on governance, ${ }^{9}$ which strengthened and generalised prior calls for openness. One Commission Communication recommended diversity on expert advisory committees, another set minimum standards for consultation of affected parties.

Expanding the scope of the assessment: since the publication of the 2001 European Communication on the Precautionary Principle, there is a notable trend in EU laws concerned with risk governance towards requiring more explicit and formal consideration of costs, benefits, and potential distributional issues resulting in inequities. The call for explicit consideration of social and economic factors in risk management as presented in the European Commission Communication on the Precautionary Principle (European Commission, 2000a) however needs further application in practice, and is associated with risk management. The Better Regulation Package also advocated formal impact assessments of new proposals, emphasizing shared definitions and objectives. Guidelines gave criteria for the analysis of environmental, economic, social, public health and ethical implications (European Commission, 2005). Further development and implementation of this package remains a focus of the Baroso Commission, and includes the implementation of a European Commission-wide effort of improved impact assessment of proposals for policies and legislation, which includes more formalised participatory procedures and the assessment of social and economic costs and benefits. In spite of these statements on principle, EU provisions for risk analysis and food safety seem to lack detailed policy guidance for the formal consideration of risks, costs and benefits (environmental, economic and social), and consequently it is not formally done in practice. Whilst policy recommendations on risk analysis (European Commission, 2000b) also emphasise the need for the expansion of the scope of the formal assessment beyond a mere focus on potential health hazards, these recommendations however have no legal standing. There are no open and formal procedures comparable to those of the US that ensure public notice, and opportunities to comment or actual face-toface involvement, of those who wish to participate in rule-making (Alemanno, 2009; König, 2007a, 2007b). In the implementation EU food law, there is a similar lack of more formal obligations.

In sum, the SAFE FOODS objectives to increase the transparency, openness and accountability of the EU food safety system can be seen as a response to calls for improved EU governance practices.

\footnotetext{
${ }^{9}$ Nine steps were adopted in 2002 to improve governance (including food safety regulation) including the Communication from the Commission Towards a Reinforced Culture of Consultation and Dialogue: General Principles and Minimum Standards for Consultation of Interested Parties by the Commission, COM (2002) 704; Communication from the Commission on the Collection and Use of Expertise by the Commission: Principles and Guidelines COM (2002) 713; Communication of the Commission on Impact Assessment, COM (2002) 276; Communication from the Commission Action Plan "Simplifying and Improving the Regulatory Environment, COM (2002) 278; Commission Communication: Better Monitoring of the Application of Community Law, COM (2002) 725; Proposal for a Council Decision Amending Decision 1999.468/EC laying down Procedures for the Exercise of Implementing Powers conferred on the Commission (amendments to the comitology procedure), COM (2002)719; Communication from the Commission the Operating Framework for the European Regulatory Agencies, COM (2002) 718.
} 
There are no Treaty provisions against adding stages to risk analysis processes such as framing and evaluation, as long as planning and integration of results in the process remains in the charge of officials entitled to do so. The SAFE FOODS recommendation to expand the scope of risk assessment is also in line with recommendations of the "Better Regulation" initiative (see also Traill \& König, this issue). Principles on the delegation of powers as well as EU food law pose some constraints on how to organize such activities within risk analysis processes. These constraints and possible solutions are addressed in more detail in the next section.

\section{Provisions of the General Food Law and food safety regulations}

The overhaul of the European laws, policies, and institutions governing food safety at the European level has been a priority since the BSE crisis and the publication of the Green Paper on Food Safety in 1997 (European Commission, 1997b). Work is still in progress at the European Commission to simplify a formerly fragmented and complex web of EU food laws. A landmark event in the simplification process was the first implementation of the Regulation (EC) No. 178/2002 establishing the general principles and requirements of food law, establishing the European Food Safety Authority and laying down procedures in matters of food safety - hereafter referred to as the General Food Law (EU, 2002). The primary goal of passing the law was to restore consumer's confidence in how food/feed safety issues in Europe are identified, assessed, and managed. Although the definitions are slightly different from those used by the Codex Alimentarius Commission (see Section 7 for an analysis), risk assessment and risk management are still largely conducted in accordance with internationally agreed principles for risk analysis (FAO/WHO, 1995, 1997).

The General Food Law provides for an integrated approach to ensure food safety across the EU Member States and across the human food and animal feed sectors. The new Regulation clarifies accountability of all legal entities involved in food production and regulation in the EU by imposing requirements on both the relevant Member State agencies and food companies. The law also provides a basis for an EU-wide rapid alert and crisis management system network of national institutes and competent authorities, in which the European Commission Directorate General for Health and Consumers (DG SANCO) plays a central role. The general principles of EU Food Law cover all products that require EU-level regulatory action, such as food additives, novel foods, and foods derived from genetically modified organisms.

The exact administrative procedures vary depending on the secondary legislation the foodstuffs fall under. For novel foods and food ingredients, the applicant who would like to place on the market a new product (usually a firm) compiles a data package with a risk assessment of the new food or substance. ${ }^{10}$ The assessment tries to determine the severity of potential health impacts and the likelihood with which they affect and how many individuals in a population. The applicant usually generates much of the data and places it into context of the wider toxicological literature. The burden of proof lies with the applicant, who is also usually responsible for generating any further data that might be required throughout the decision-making process. The dossier is then submitted to a Member State. Another model is offered by Regulation (EC) No. $1829 / 2003$ on genetically modified foods and feed (EU, 2003), which provides that the Member State refers the risk assessment to the EFSA for a detailed scientific evaluation.

\footnotetext{
10 The assessment tries to determine the severity of potential health impacts and the likelihood with which they affect and how many individuals in a population. The applicant usually generates much of the data and places it into context of the wider toxicological literature.
}

The General Food Law endorses the model of risk analysis separating risk assessment and risk management, in which the following steps must be distinguished: risk assessment, risk management, ${ }^{11}$ implementation, and enforcement of the law. ${ }^{12}$ Implementation and enforcement are largely handled at the level of the Member States. Within the EU system, proposals for decisions are usually drafted by DG SANCO officials, and decisions are taken by regulatory committees of representatives of Member States. The assessment that underlies the decisions is done by Scientific Committees of "independent" scientific experts asked not to consider any national or other interests. The European Commission officials, in this case also the risk managers, initiate the process by defining terms of reference for the assessors. It is also up to the officials within DG SANCO to draft proposals by taking into account both the expert panel's risk assessment and other broader considerations that may affect choice of policy options. A regulatory committee of representatives of Member State authorities then decides through a weighted voting system whether to accept the commission proposal. If the regulatory committee's opinion is not in accordance with the proposed measure, or if no opinion is delivered, the question is referred to the Council of Ministers. The Council of Ministers can approve or reject a European Commission proposal with a qualified majority of Member States votes. If rejected, the European Commission prepares a new proposal. If the Council of Ministers takes no decision within three months, or lacks a qualified majority to oppose the proposal, the European Commission shall adopt the proposal.

Framing and evaluation: whilst there are comparatively few mandatory provisions for stakeholder involvement, there are also few restrictions, as long as involvement follows the rules on the distribution of powers laid out above. At the EU-level there are few legal obligations that specify concrete procedural mechanisms for stakeholder involvement in the implementation of food safety legislation, perhaps even fewer than for legislative changes. ${ }^{13}$ There are, however, no apparent legal restrictions to instituting additional steps in risk analysis, such as framing and evaluation recommended by the SAFE FOODS consortium.

To the contrary, emerging sectoral regulations at EU-level seem to underscore SAFE FOODS recommendations. For example, a recent new food-related regulation, Regulation 1925/2006 on food fortification, specifies a new procedure: Article 3 makes obligatory the consultation of interested parties. Article 14 provides that the European Commission has to rely on assistance of the new Advisory Committee on the Food Chain and Animal and Plant Health. Some guidance on cost-benefit analysis is apparently also being developed.

Expansion of the scope of the assessment: the General Food Law states that food risk analysis should be based on scientific risk evaluation by the European Food Safety Authority (EFSA). EFSA's other

\footnotetext{
${ }^{11}$ Article 22 (2) of the General Food Law provides that the Authority shall provide scientific advice and technical support for the Community's legislation and policies in all fields, which have direct or indirect impact on human food and animal feed safety. It shall provide independent information on all matters within these fields and communicate on risks.

12 The General Food Law (EU, 2002) provides common elements for decisionmaking procedures for all products that require EU-level approvals, such as food additives, pesticide residues in food, and novel foods, including foods derived from genetically modified organisms. There are slight variations between the exact procedures for different secondary legislation. The procedure for Novel Foods is as follows. The European Commission DG SANCO administers the review process. The European Food Safety Authority administers expert panels that review the risk assessment submitted by applicants intending to place a Novel Food on the European market.

${ }^{13}$ Communication from the Commission: towards a reinforced culture of consultation and dialogue (European Commission, 2002a). There are, however, no open and formal procedures comparable to, for example, the US procedural Statutes including the 1946 Administrative Procedure Act and the 1972 Federal Advisory Committee Act that ensure public notice, and opportunities to comment or actual face-to-face involvement, of those who wish to participate in rulemaking.
} 
legal objectives include the improvement of the quality of risk assessment of food-safety-related issues, and to further develop the science of risk assessment. The Authority responds to questions raised by the European Commission, the European Parliament, or Member States, or it may address scientific issues on its own initiative. EFSA is set up as an independent agency. It is controlled by a Management Board whose members act in their independent capacity, not as national representatives. EFSA's remit is restricted to providing risk assessments and engage in risk communication. ${ }^{14}$ The law clearly limits the risk assessment by EFSA to the consideration of health impacts in terms of order of magnitude of health effects and their likely distribution (EU, 2002).

The EU General Food Law providing the framework for governance of food safety in the EU refers to the precautionary principle (EU, 2002). Article 6(3) provides that officials in the European Commission, when writing the proposal for a decision that is to be voted upon by Member States shall take into account the results of the risk assessment (in particular the opinions of the Authority), and other factors legitimate to the matter under consideration, and the precautionary principle (Article $7(1)$ ) in order to achieve the general objectives of food law established in Article 5. The possible legal interpretation is that if, in situations of uncertainty (and the question of legal trigger of the precautionary is a different one addressed elsewhere), such "other legitimate factors" should be formally assessed; before they weigh into decision-making, this would need to be organized under DG SANCO.

At present there is however little formal legal guidance or transparency on what these other legitimate factors are, how they are considered, and who is consulted on the matter. It is very much left to the discretion of the officials. The General Food Law clarifies that health assessment by EFSA can only address the probability and severity of health impacts as part of health assessment. Risk-benefit comparison or trade-off analysis requires health utility or monetary measures which fall under social or economic assessment. To date, EFSA's opinion usually remain the only publicly available document of advice that underlies the formulation of a European Commission proposal for a decision that is to be voted upon by a regulatory committee.

Prominent examples in secondary legislation that also refer to the precautionary principle include the revised Directive 90/220/ EEC on the deliberate release and placing on the market of genetically modified organisms (GMOs), which, after lengthy discussions, was decided not to provide any legal basis for addressing the so-called fourth hurdle (social and economic impacts of innovations), which was replaced by Directive 2001/18/EC. The REACH Regulation for a simplified system to regulate chemicals by a European Chemicals Agency that was implemented only in 2006, 4 years later than the General Food Law, now provides the legal basis for establishment of an expert agency with two committees: a Socio-economic Committee in addition to the Scientific Committee (EU, 2006). The European Commission proposal for a Socio-Economic Committee in a chemicals agency may indicate that the political winds may be turning from overemphasizing the separation of the "scientific" from the "political" to addressing the concern of providing adequate grounds for coordination between risk assessors and risk managers.

The objectives of the SAFE FOODS Risk Analysis Framework of improving the paper trail of "other legitimate factors," such as social and economic considerations that often weigh into risk management decisions, are somewhat reflected in EU law that makes

\footnotetext{
14 Article 22 (2) of the General Food Law provides that the Authority shall provide scientific advice and technical support for the Community's legislation and policies in all fields, which have direct or indirect impact on human food and animal feed safety. It shall provide independent information on all matters within these fields and communicate on risks.
}

reference to the precautionary principle. But as stated above, rules on roles of agencies and types of information that can be considered by each are often provided by the specific legislation.

In sum, there are some legal constraints to organising the four distinct activities framing, assessment, evaluation, and risk management, in particular if they involve participation of experts and affected parties. EU law has strictly limited definitions of the roles stakeholders, experts, European Commission officials, and regulatory committees with Member State representatives can play. Linked, there are also rules constraining how outcomes from the four different activities may be used in the risk analysis process. EFSA's remit as specified in its founding law precludes the involvement of lay people in expert committees in the actual process of "decision-making." Framing including definition of scope of assessment and terms of reference for the assessors, and evaluation leading to an interpretation of results and weighing of costs and benefits and distributional questions will have to be organized under the responsibility of the European Commission and lead to advice that is to be considered by EU officials as additional information towards formulating a European Commission proposal to a regulatory committee. By law, there can be no formal involvement of experts or stakeholders in "decision-making" as such.

One solution suggested by the SAFE FOODS group to distinguish the activities of framing, assessment, evaluation, and decisionmaking, and to consider framing, assessment, and evaluation as activities that serve to prepare reports that are considered as advice to decision-makers and can inform both the writing of the proposal by Commission officials as well as the voting process in regulatory committees. The role of EFSA is by law restricted to the provision of advice on health risk and benefits. However, nothing legally precludes DG SANCO to conduct assessments of economic and social impacts, and to organize a more formal evaluation step (the question on resource constraints is addressed in Section 5). The reference to the precautionary principle in the General Food Law provides an adequate legal basis to formally consider economic and social impacts and their distribution in decision-making, at least in situations where the principle is deemed to be applicable. It follows that some of the discussion in the framing stage may consider whether the situation triggers applicability of the principle, as well as other common sense considerations. This then allows considering whether the scope of the risk assessment may be expanded to including economic and social impacts. In sum, all proposed measures by SAFE FOODS are in line with the law, the only legal restrictions relate to who does what.

\section{Current practice: implementation of food law in the European administrative space}

Often invisible to the citizen is the integrated network administration of Member State and European Institution bodies that not only takes charge of implementation of EU food law. (Hofmann \& Tuerk, 2006). This network consist of officials of competent authorities of EU Member State governments and the EU institutions and agencies, experts, and often also engaged private actors. The role of the network of those familiar with and in charge of food safety governance at Member State and EU-level, in the public and private sector often goes beyond implementation and involves other governance activities such as setting agendas and formulating policies. The conditions for accountability and legitimacy in such an integrated network differ between these three different governance activities (Hofmann, 2008). In practice, iterative governance processes result in changes in distribution of powers between legislating and implementing functions, in particular if this takes in a system of decentralised, yet cooperative administrative structures as the EU food governance system. New approaches are required to 
make this state of affairs visible and to enhance the accountability of those involved (Hofmann, 2008). By recommending the formalisation and public documentation of framing, evaluation, and assessment of social and economic impacts, activities that are to date usually carried out less formally and transparently, the SAFE FOODS Risk Analysis Framework can be seen to directly respond to this call, as set out in more detail below.

Framing: even though their involvement is rarely formally documented in the EU, stakeholders have important opportunities to influence EU-level policy processes. ${ }^{15}$ First, the European Commission in initiating the legislative process usually consults stakeholders, such as associations representing European industry sectors or consumer groups, on early draft policies and proposals for legislation. Members of the European Parliament playing active roles in the legislative process, often welcome information from those they think represent the interests of their major constituents. In addition, EU-level interest groups also lobby the permanent representatives of Member States at the Council of Ministers. This is done regularly by organising round table discussions or by creating ad hoc consultative committees of stakeholders and experts. The openness of Member State governments to different stakeholder interests, which may be reflected in positions taken in the Council of Ministers, is significantly determined by the political appointees in concerned government departments, which in turn depends on the ruling party(ies) in Member States.

More specifically relating to "stakeholder engagement," the EU institutions, and the European Commission services in particular were likened to a flock of administrative geese that fly towards improved engagement at different speeds and on different trajectories. ${ }^{16}$ Most practitioners consulted in development of the SAFE FOODS framework considered stakeholder involvement in risk analysis indispensable, but called for a deeper analysis on how this happens already today, and on what the value and drawbacks would occur from further formalizing this. For example, DG SANCO just obtained recommendations from its "Healthy Democracy" initiative, in which a group of experts was asked how current practices of stakeholder consultation at the commission might be improved (European Commission, 2007). The main problem identified by this group was the lack of representation of diverse groups of stakeholders across Member States. Organized civil society actively seeking direct input in EU policy, usually come from two or three larger Member States with a strong or long-standing tradition of participatory politics (such as the UK). The same few groups usually also have the loudest voice in Brussels-based EU-level groups. Input from across all 27 Member States would be preferred as cultural variations are expected, in particular on food-related matters. One main challenge is thus "how to engage the unengaged"?

Therefore, the activity of framing per se, is nothing new, but has not found as yet a formal legal recognition. Officials from the European Commission and EFSA emphasized that although there may be little or no formal system for framing, people employed at EFSA and the European Commission do talk to each other on an ongoing basis during all stages of decision-making, even if this is not always formally documented. Staff from the DG SANCO takes part in EFSA Scientific Panel meetings as observers. Likewise, staff from EFSA takes part in DG SANCO meetings in observer roles (Gabbi, 2007).

\footnotetext{
15 The main stakeholders consulted in the governance of food safety at EU-level include consumer groups and food industry associations. The main consumer group active in the area of food safety at EU-level is BEUC, the European Consumers' Organisation. The food industry in Europe has contributed to establishing four main lobby groups that aim to influence European policy processes: the association of the European retail and distribution industry "EuroCommerce"; the European Food and Drinks Federation "CIAA"; the European Crop Protection Association "ECPA"; and the European biotechnology industry association "EuropaBio".

16 This analogy is borrowed from Robert Madelin's key note address given at the 11 May 2007 workshop organized by Marion Dreyer and Ortwin Renn.
}

DG SANCO and EFSA staff together developed a guidance document for formulating the terms of reference for assessments. Stakeholders are often consulted, including by organising workshops on specific issues conducted by EFSA and by DG SANCO. EFSA has, for example, organized stakeholder consultations and workshops to consult on specific issues such as foods derived from genetically modified crops. In framing policy and legal issues, this information is considered together with information from other meetings with stakeholders. Concerns voiced, however, are that DG SANCO lacks staff to administer ever multiplying committees. Coordination between existing structures was already difficult enough. Proposals for improvement should focus on remits and activities under existing structures.

At EFSA, initiatives and events seeking stakeholder input are conceived of as separate activities from meetings of scientific expert committees. There are different types of formal events that serve to inform EFSA staff and scientific experts on panels about stakeholder views, including Member State authorities, and connect them to experts on specific issues in other world areas. ${ }^{17}$ For example, there are "stakeholder colloquies" which serve as platform for an open dialogue with as many stakeholders as there are. Alternatively, there are "public consultations via the web." These are usually held on "hot topics" such as cloning, GMOs, pesticides, feed additives, genotoxic and carcinogenic substances. In general, EFSA's main concern is to identify the main stakeholders - and whether there is a wider audience EFSA should try to reach - at the national level, without stepping on the toes of national authorities, which likely already have relationships with them. As experienced by DG SANCO, stakeholders eager to participate usually originate from one to three main EU countries, and are far from being evenly distributed across all 27 Member States.

On the other hand, in spite of these varied activities that are intended to contribute to improved participatory framing, most participants from industry and non-governmental organisations that attended the second SAFE FOODS stakeholders consultation in Brussels (in March 2007) indicated that they would welcome an opportunity to provide more formal input at the early stages of issue definition and framing (SAFE FOODS, 2007). One participant thought that current methods of soliciting stakeholder input of the European Commission, and in particular commonly used internet-based questionnaires, were "narrow and inflexible" and designed to yield answers officials were looking for. True deliberation, as advocated in the Post Normal Science community (Funtowicz \& Ravetz, 1992; Ravetz, 1999) was not an option in most settings provided. Whilst this view was not widely defended - many participants appreciated some means for providing input thoughts on more open and flexible methods for stakeholders to provide advice would be welcome.

The SAFE FOODS proposal to establish an "interface committee" at which assessors, managers, and stakeholders participate in framing was eyed with apprehension by most EU officials consulted. One reason, and perhaps the main reason for the apprehension, was that a stakeholder committee was just established in the form of the Advisory Committee on the food and feed chain. The timeframe from its first conception to it starting to be in working order and properly administrated was several years. DG SANCO, apart from working closely with EFSA, has set up two additional permanent bodies which are involved in decision-making on food safety policy. First, there is a regulatory committee with representatives from the EU Member States that is involved in decision-making on all measures proposed/taken by DG SANCO. The Standing Committee on the Food Chain and Animal Health

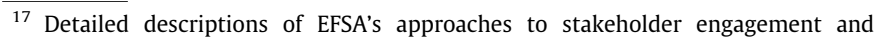
documentation of each event can be found on EFSA's website at http://www.efsa.europa.eu/EFSA/EventsMeetings/efsa_locale-1178620753812_partstakeevents.htm.
} 
was established following the adoption of the General Food Law. The Committee's mandate covers the entire food supply chain, ranging from animal health issues on the farm to the product that arrives on the consumer's table, therefore significantly enhancing its ability to target risks to health wherever they arise in the production of our food. It is chaired by a European Commission representative. Secondly, in 2004, the European Commission created an Advisory Group on the food chain and animal and plant health and established a consultation procedure on the food chain and animal and plant health through representative European bodies. These structures allow for key stakeholders including farmers, the food industry, retailers, consumer organisations, and others to advise the European Commission on food safety policy. The Advisory Group meets at least twice a year and consist of up to 45 members from EU-level associations.

In practice, the SAFE FOODS recommendations of developing more systematically routines for documentation and relation to the rest of the risk analysis process of framing and evaluation activities would perhaps at first present an additional burden to develop such routines, but may in the end be perceived to save lots of time and effort at coordination and respond to great shortfalls in transparency and accountability of decentralised cooperative systems.

Assessing uncertainties and expanding the scope of assessment: EFSA aims at a greater transparency in the process of risk assessment, including timeframes, and a better liaison with Member States and stakeholders. EFSA has a Scientific Committee and Eight Panels consisting of leading European experts, active in different areas of food/feed production. There are no provisions for participation of social scientists, consumer representatives, members of a citizen's jury, or other stakeholders on the expert panels, likely because of the legal restrictions of EFSA's role to health and environmental health impact assessment, as described in Section 4.

The SAFE FOODS recommendation of greater use of probabilistic analyses for better characterizing uncertainty and variability in risk is fully compatible with current practice. The SAFE FOODS recommendation on application of the NUSAP tool should also be considered for broader adoption for better characterizing and communicating on key figures in assessments and how they have been derived at EU-level (see Section 2 and König et al., this issue).

In the case of the EU, due to legal constraints, risk-benefit assessment that can be conducted by EFSA has to explicitly exclude the use of all methodologies that would serve to measure social or economic aspects, including the utility-implications of diverse health impacts at the population level, as this can be seen to be in the realm of risk managers. ${ }^{18}$

However, prevailing practice consisting of making publicly available only documentation on the determination of point estimates for the likelihood and severity of adverse health impacts has at least two severe drawbacks: it is inadequate for good decisions seeing risk in context required for proportional resource allocation and does not foster transparency on considerations weighed in decision-making. Furthermore, most practitioners consulted considered the SAFE FOODS introduction of health risk-benefit assessment desirable and a great step forward by all, especially if

\footnotetext{
$\overline{18}$ In a letter from 16 February 2007 (Ref.: JK/gf (2007) out 1992408) from EFSA Director Catherine Geslain-Lanéelle to Prof. Vittorio Silano support was expressed for setting up a Scientific Committee on Health Risk-benefit Assessment. The letter however also stated that "It should be well-understood that health-benefit assessment does not include an economic or social component." The new Committee obtained the mandate to prepare a guidance document on methodology, approaches, tools, and limitations by February 2009. Given the mandate's restriction, this is particularly challenging; as it excludes social and economic components, it by definition excludes any meaningful scale for common measurement and comparison of disparate health impacts.
}

methods for weighing diverse health impacts are further developed. This will improve the public health outcome of decisions.

Given the separation of the remits of risk assessors at EFSA and risk managers at DG SANCO in regulatory committees of Member States, the scope of the risk-benefit assessment conducted by experts at EFSA was considered a sensitive and controversial matter. This goal is already institutionalised in the form of an activity of the EFSA Scientific Committee on risk-benefit assessment. The remit of the Working Group is, however, to a certain extent contradictory, as it includes the goal to seek a practicable common denominator for the comparison of disparate health effects, but precludes any consideration of social and economic impacts. Commonly used measures for comparing disparate health impacts however already quantify these in terms of social "health utility scales" or monetary units. Work towards wider use of Quality-Adjusted Life Years (QALYs) may circumvent this problem as QALYs separate the assessment of probability and severity of health impacts and their relation to established health utility scales through population surveys. EFSA could focus on establishing the probabilities and severity. The required surveys to relate the probabilities to health utilities at the population level would be conducted and interpreted by others. Structurally there could be two groups: natural science experts at EFSA and a "quality of life commission." Conclusions and recommendations from these two groups would need to be integrated in one report to provide to regulators. Such recommendations will need to be checked for compliance with the General Food Law.

The health impact prioritization system developed under the auspices of the SAFE FOODS integrated platform, which ranks hazards in several classes of severity/impact (Bos et al., 2009), was designed for prioritizing risks of different compounds, e.g. in risk-benefit and risk-risk considerations. The intent was to help to bridge the gap between recommendations of risk assessors and risk managers, and make them more easy to interpret. For this prioritization system, information on at least three parameters is needed: (1) the fraction of the population at risk, (2) the type of effect(s) expected to occur, and (3) the size (severity degree) of the expected. The system defines four categories representing an increasing impact on human health. Deployment of such a system within EFSA could be envisaged, and is largely compatible with its legal restrictions and capacities.

In sum, the integrated decentralised network of administrations involved in food safety governance in the EU in practice would require more formalised activities to achieve greater transparency and accountability on who is involved and at what stage of the food risk analysis processes. The SAFE FOODS recommendations to stage formally documented framing and evaluation processes and formally assess social and economic impacts respond to this call.

\section{Potential implications with regard to judicial review}

As demonstrated above, the SAFE FOODS recommendations of instituting a risk analysis procedure with four activities of framing, assessment, evaluation, and decision-making are compatible with current EU food law and institutional set-ups, provided care is taken to implement these recommendations according to the analysis in this paper. In this section, it is argued that, for the sake of transparency, a formal assessment of these will certainly help, also to facilitate the Court's judgment on whether the European Commission disregards public health considerations in appropriately in using this discretion, and to help the system to develop case law that will make the outcome of such decisions more predictable. 
The legitimacy of proposals from public administration on food safety measures will continue to be challenged. Most of the SAFE FOODS recommendations relating to the risk analysis procedure suggest improvements for how administrative decision-makers should appraise or propose standards for food safety issues. Health and environmental safety issues give rise to an ever increasing number of legal cases in which the legitimacy of public administration is challenged. One reason for such disputes is that decisionmaking on health and environmental risks requires the delegation of considerable discretion to public officials. Furthermore, the question of whether the exercise of that discretion was legitimate is often not easy to judge, be it due to scientific uncertainty, changes in social norms over time, or other shifting grounds making legitimacy judgments in this area a moving target (Fisher, 2007). Such judgments will usually consider the reasonableness of the decisions and non-arbitrariness of the use of the power, assessed also based on principles such as consistency with past decisions and proportionality.

Judicial review of regulatory action per se has its merits as one of several possible mechanisms that offers an entry point and improved connection of interested and affected parties in rule-making processes. In the Directive $90 / 220 / \mathrm{EC}$ on the deliberate release and the placing on the market of GMOs, for example, the safe guard clause assured the possibility for Member States to start such a review process of European Commission decisions in the light of new evidence (see also Kuiper \& Davies, this issue). Repeated resort of Member States to that clause and subsequent joint statements on requiring revision of the Directive itself, evidences the normative malleability of law, the revised Directive 2001/18/ EC now requiring labelling, monitoring provisions, and a time-limited approval. This is just one example of the normative nature of law and constant changes adapting to shifting understandings of government and governance and prevailing norms in a society. In this case, legal disputes led not to changes in a decision, but to the normative re-framing of the legislation.

Hence legal disputes on how to govern risks will help courts to readjust to prevailing social norms and reconsider the purpose of regulatory action and fairness, in the end affecting and contributing to shaping norms and principles determining the purpose and legitimacy of public administration. This in turn shapes the basis for what the SAFE FOODS goals of improved transparency and accountability ${ }^{19}$ in the process mean, as the underlying legal framework often already provides a basis defining the purpose of regulatory action and which considerations the decision-maker can take into account and has to account for.

In the absence of a legal framework questions of legitimacy of public administration are all the more salient, and administrators are all the more vulnerable to critique. One of the first times when the European Court of Justice had to judge on different interpretations of scientific facts by two expert advisory bodies, was in July 1999 when France refused to lift the embargo on British beef that had been ordered by the European Commission. ${ }^{20}$ The Commission tried to posit the scientific advice by an EU Committee as superior to a national committee. But the Court ruling voided all review of scientific facts and just condemned France for not lifting an embargo when the EC law said so. Calling public administration to account often challenges what their role really is.

\footnotetext{
${ }^{19}$ Accountability: being liable to be called to explain or justify one's conduct in an intelligible way. At the root of the word's lie both the word "account" as in narrative, as well as the later meaning of "account" as in calculation (Oxford Advanced Learners Dictionary of Current English. AS Hornby.). SAFE FOODS makes the case that for improved public accountability of risk analysis procedures more systematic and publicly documented analysis of the objective, and who benefits and who looses is required.

${ }^{20}$ Case C-1/00, commission v. France [2001] ECR I-9989, as described by Alemanno (2006) and Vos (2000).
}

6.1. More systematic analysis of purpose, and fairness - who gains and who looses

Judicial review by the European Court of Justice has repeatedly confirmed the focus of the assessment to be on health risks as defined by the Food and Agricultural Organisation (FAO and World Health Organisation (WHO), and that risk assessment includes hazard identification, characterisation, exposures assessment, and risk characterisation. In 1999, the distribution of power among the Council of Ministers, the European Commission, and the expert committees was clarified by a ruling of the European Court of Justice. This case, which concerned the use of antibiotics as growth promoters in animal husbandry, concluded that the Commission and the Council may disregard conclusions drawn from expert opinion, as expert committees have "neither democratic legitimacy nor political responsibilities" - whereas the European Commission's authority "is rendered legitimate and democratically accountable" pursuant to the Article 211 of the EC Treaty, and to the control of the European Parliament. ${ }^{21}$ In the same case, the European Court of Justice has also clearly stated that "scientific legitimacy is not a sufficient basis for the exercise of public authority."22 In a subsequent case where the European Commission disregarded two opinions of the "Committee for Veterinary Medicinal Products" recommending that this progesterone product would require no maximal residue limits and hence an unconditional marketing approval, the European Court of Justice confirmed that the Commission had the discretion to consider other factors than the mere science. ${ }^{23}$

\subsection{Risk analysis of foods and the benefits of judicial review}

Legal challenges of decisions proposed by administrations can relate to all aspects of process, content, context or outcome of the decision (see for example Alemanno, 2007a, 2007b; Fisher, 2007; Jasanoff, 1995). Judges usually analyse the degree of adherence to legally prescribed procedures on the one hand, and whether proposed decisions are reasonable and non-arbitrary (Fisher, 2007). These criteria have proven central in particular in cases where significant discretion was exercised by administrators, as for example where the European Commission proposals departed from scientific advice. Complete social deconstruction of decisions and underling scientific findings is however not desirable, either. Judges have the discretion to close debates they do not deem to be sufficiently fruitful to justify the administrative resources spent (Jasanoff, 2006). The two main tools to achieve rapid closure are the legal principles of "stare decisis" (that is to follow earlier judicial decisions when the same issues arise again), or judicial deference to advice from agencies or expert bodies. Decisions on closure will often reflect a judge's view on whether issues of delegation and fairness have been adequately addressed (Jasanoff, 2006).

The SAFE FOODS recommendations on procedure require a more reflexive approach to how transparency is achieved, and to whom. The two additional stages of risk analysis open up options for new procedural checks and balances that not only allow raising and answering questions on the quality of science underlying claims, but they also create spaces for more fundamental question during the framing stage on the purpose of the science and regulatory action, and during evaluation on whether the science presented is adequate for and to legitimize that purpose. The latter two questions should not only be judged by scientists, but also

\footnotetext{
21 European Court of Justice ruling T-13/99, Pfizer at paras. 200-201.

22 Case T-13/99 Pfizer Animal Health v. Council, 2002 E.C.R. II-3305 paragraphs 156 and 201, respectively.

23 Cases T-344/00 and T-345/00, CEVA Sante Animale SA CER [2003] II-229, and case
} C-198/03 P, commission v. CEVA/Pfizer, [2005] ECR I-6357. 
by interested and affected parties. Implementing guidelines on how to formalise these stages with legal significance will likely be refined in response to judicial review of cases where they have been applied, over time.

Moreover, recommendations on practices to enhance the transparency on the role of "other legitimate factors" in decision-making processes will also likely need to be refined and clarified through judicial review. The implementation of the REACH Regulation (EU, 2006) and in particular the coordination of the solicitation of advice from both the Scientific Committee and the Socio-Economic Committee of the new chemicals agency will likely give rise and be indicative of the types of legal challenges that will also increasingly be made in the arena of decision-making on food safety. The main aspect that will remain to be clarified are boundaries between impacts considered legitimate and relevant on an EU- or world-wide basis and impacts that are considered too regional or local and that are seen to negatively impact trade. But in the interest of achieving greater transparency and bringing decisions closer to citizens in the information age, and creating greater accountability, opening up the black box of regulatory objectives, and tensions between health and environmental objectives, trade objectives, and fostering active industries, by placing it under judicial review may well be warranted. In particular in the WTO system, where the Appellate Body now increasingly starts to acknowledge and has inferred in past rulings that it recognizes often science alone is not sufficient for choice of regulatory action (Alemanno, 2007b), it will be interesting to see more case law. These questions may also open up new fields of research on attempts to better define types of impacts according to their geographic reach or regional or local confines.

\section{Are SAFE FOODS recommendations compatible with the WTO food safety governance system?}

One key prerequisite for the official adoption of SAFE FOODS recommendations within the EU-level food system is that this does not present unnecessary grounds for conflict with provisions of the World Trade Organisation (WTO). The food safety governance systems of the WTO and the EU allow for individual members to define their chosen level of protection, and refer to similar principles to assess the legitimacy of decisions vis a vis impact on trade flows. This section compares the general principles set out in international law and policies, procedural provisions and practice for making decisions on food safety under the WTO and EU, and assesses the compatibility of the main SAFE FOODS recommendations with them. This brief comparative outline intends to set the stage for future, more in-depth analyses.

\subsection{General governance principles and policies}

The main legal instruments relating to the functioning of the WTO to food safety governance laying out basic legal principles is the Agreement on the Application of Sanitary and Phytosanitary Measures (SPS Agreement). The SPS Agreement makes reference to the Codex Alimentarius Commission (CAC) as one main standard setting body.

The SPS Agreement sets out rules for the protection of consumer health and the environment. It permits WTO Members to take legitimate measures to protect life and health of their consumers while prohibiting them from using those measures in a way that unjustifiably restricts trade. In the SPS Agreement Article 2 (2) states that "Members shall ensure that any sanitary or phytosanitary measure is applied only to the extent necessary to protect human and animal or plant life or health, is based on scientific principles and is not maintained without sufficient scientific evi- dence except for as provided in paragraph 7 of Article 5." Article 5 (1) states that Member States' measures must be based on a proper risk assessment. Article 5(7) states that "in cases where relevant scientific evidence is insufficient, a Member may provisionally adopt sanitary or phytosanitary measures [...]."

Framing and evaluation: within the SPS law, there are no clauses in any way preventing the formal conduct of framing and evaluation activities. To the contrary, more general policy recommendations from bodies associated with the WTO food governance systems make recommendations along similar lines.

In intergovernmental recommendations on risk analysis policies, the definition for risk management is "the process of weighing policy alternatives in the light of risk assessment and, if required, selecting and implementing appropriate control options, including regulatory measures" (FAO/WHO, 1997). According to the Joint Expert Consultation on Risk Communication interactive communications are necessary and essential to identify social, economic, religious, ethical, and other concerns, so that these can be openly considered and addressed (FAO, 1999). Risk communication, defined as interactive communication among all interested parties, is an integral part of risk analysis, and a necessary and critical tool to appropriately define issues and to develop the best risk management decisions at every stage of the process. It also facilitates the identification and weighting of policy and decision alternatives by risk managers in the risk analysis process. To the extent that it is practical and reasonable, interested parties should be involved in identifying management options, developing the criteria for selecting those options and providing input to the implementation and evaluation strategy. These parties may include (but should not be limited to) consumer organisations, representatives of the food industry and trade, education and research institutions, and regulatory bodies. Such consultative process can be implemented in many ways, ranging from public meetings to opportunities to comment on public documents. Inputs from interested parties can be introduced and considered at every stage of the risk management policy formulation process, including evaluation and review. This tends to assure transparency, to facilitate consistency and to improve the risk management process.

This recommendation on processes for setting standards underlying WTO food safety governance is formulated in more concrete and explicit terms as relates to inclusiveness than several initiatives advocating within the European Commission White Paper on Governance and the "Better Regulation package" (see Section 3) advocating more open and inclusive approaches to governance. The FAO recommendation on risk communication has clear parallels with the SAFE FOODS recommendations to institute a formalised framing and evaluation stages in risk analysis.

Considering uncertainty in assessments: the 1995 Joint Consultation also considered ways in which uncertainty was associated with risk assessment, and called for greater attention in assessing and communicating uncertainties. Tools recommended by SAFE FOODS, such as the NUSAP method, are a response to redress to insufficient attention of experts on how uncertainties are assessed, described and communicated (see Section 2, and König et al., this issue).

Scope of assessment: the SPS Agreement refers to risk assessment procedures, places the concept of "sufficient scientific evidence" central to determining whether a preliminary regulatory measure to prevent potential harm is warranted, and does not make an explicit reference to precaution. It is therefore, at present, unclear, whether WTO legal instruments, because of their focus on "sufficient evidence" as a basis for regulatory measures, and by refraining from explicit reference to risk management, can serve to legitimize the consideration of "other legitimate factors" in the choice of regulatory measures (Alemanno, 2007a, 2007b). In intergovernmental policy recommendations, the general process of risk 
assessment was largely defined in the 1995 Joint FAO/WHO Expert Consultation on risk analysis. The risk is determined as the product of the likelihood of the occurrence of harm and the magnitude or severity of the effect.

The Appellate Body in the case on EC measures concerning meat and meat products (hormones), 16 January 1998 \# 16, stated that "there is no need to assume that Article 5.7 exhausts the relevance of the precautionary principle." It also clarified four cumulative conditions for the application of Article 5.7: such provisional sanitary and phytosanitary measures must be (i) imposed in respect of a situation where scientific evidence is insufficient, (ii) adopted on the basis of pertinent information, (iii) may not be maintained unless the Member seeks to obtain additional information necessary for a more objective assessment, and (iv) reviews the measure accordingly within a reasonable period of time (see, for example, Alemanno, 2007a, 2007b; König, 2002).

More specific statements on the role of framing, evaluation and the need to expand the scope of assessments are contained in the CAC 17th procedural manual. The manual sets out "General Principles on Risk Analysis" that comprise risk assessment, risk management and risk communication, and "General Principles on the Role of Science and Other Legitimate Factors". For the purpose of this paper, the provisions of this manual are considered to have a similar function and will thus be compared to the procedural mandates on risk analysis in the EU General Food Law and secondary legislation on specific foods and food ingredients (see Section 4).

\subsection{Comparing CAC rules of procedure to EU food law}

One fundamental principle of risk analysis under the CAC and the EU institutions (see Section 4) is the institutionalised separation of risk management and risk assessment activities. The CAC risk analysis process is very similar to that at the EU-level in that the European Commission coordinates decision-making by Member State committees, based on advice by scientific committees such as the Joint Expert Committee for Food Additives (JECFA) and the Joint Meeting on Pesticide Residues (JMPR). These basic distinctions between the roles of risk assessors, risk managers, and affected parties are maintained in the SAFE FOODS Risk Analysis Framework, even if their interaction within multi-level governance administrative networks and their mutual influence on each other is not, and should not always be as clear cut (see Sections 5 and 7.3).

Framing: several activities that are described in the CAC rules of procedure section on "general principles for risk analysis" as part of the preliminary steps of risk management are comparable to activities of the SAFE FOODS "framing stage." EU food law features no comparably detailed description of activities setting the scene for risk assessment and risk management. According to the CAC rules, the "preliminary stages of risk management" include defining the issue and planning the decision process. After a risk issue has been brought to the attention of the CAC, a risk profile is established. The risk profile is a description of the food safety problem and its context. A risk profile often includes a brief description of the situation, product, or commodity involved; the values expected to be placed at risk, (e.g. human health, economic concerns); potential consequences; consumer perception of the risks; and the distribution of risks and benefits. Establishing the risk profile also involves the identification of aspects of risks relevant to risk ranking, setting the risk assessment policy and the choice of safety standards and management options. Subsequently, the CAC rules of procedure prescribe that risk managers and assessors jointly develop the risk assessment policy, defined as "guidelines for value judgement and policy choices which may need to be applied at specific decision points in the risk assessment process, to protect the scientific integrity of the risk assessment." These guidelines should be documented so as to ensure consistency and transparency. Examples of risk assessment policy setting are establishing the population(s) at risk, establishing criteria for ranking of hazards, and guidelines for application of safety factors. The subsequent commissioning of the risk assessment, including setting the terms of reference for the experts, takes into account the risk profile and risk assessment policy.

The CAC provisions for risk profiling, and defining the risk assessment policy are considered part of risk management, but bear many similarities to the SAFE FOODS recommendations towards a formal framing step that serves to define the issue, identify alternative regulatory options in broad terms, and to plan the assessment and the entire risk analysis process. In the SAFE FOODS Risk Analysis Framework, too, framing is an activity coordinated by risk managers and the output serves as advice to the decision-makers - this is akin to the CAC described actions of preliminary preparatory steps of risk management. One difference is that the SAFE FOODS project recommends making formal and publicly available reports of this stage - but this recommendation is not seen as incompatible with the CAC definitions of risk management activities. Furthermore, SAFE FOODS offers recommendations on tools to participate in the risk analysis process, such as the ethical matrix, which seems very compatible with Codex recommendations on better integrating communication practices as part of risk management (see Section 2, and König et al., this issue).

Evaluation: the concept of risk management, as defined in the CAC rules of procedure 17th manual, includes issue definition, process planning as well as decision-making steps. Risk management strategies include authorisation, implementation of risk management measures to minimise the risk, and banning of a product or process in question to prevent the risk. Examples of risk management measures for conditional approvals include labelling of products in order to inform the target group at risk as done for food products that contain major allergens, requirements for further research or post-market monitoring provisions to better characterise the risk, or implementation of measures to restrict use of the product or process, where tools include increased taxation or liability regimes for polluting products or processes.

According to the CAC rules of procedure, risk management decisions should be based on risk assessment, and "other legitimate factors" should be taken into account, when relevant for the health protection of consumers and the promotion of fair practices in food trade. This should be done in accordance with both the statement on principles concerning "the role of science in the Codex decisionmaking process" and "the extent to which other factors are taken into account." Human health protection should be the primary consideration, with other factors (e.g. economic costs, benefits, technical feasibility, risk perceptions, etc.) being considered as appropriate.

Assessing uncertainties: responding to a call in the CAC procedural manual to direct more attention to the description of uncertainties in risk assessment, the SAFE FOODS project offers tools for the improved description of uncertainty. The NUSAP method is generally applicable for this purpose (see Section 2). The probabilistic risk modelling tools that were further developed for use in the EU under the SAFE FOODS project are certainly compatible with risk analysis principles as defined by the CAC procedural manual, as far as sufficient data exists for their deployment for particular risk issues.

Expanding the scope of assessment: the scope of risk assessment relates strictly to the consideration of the natural science data necessary to follow the model for risk assessment which consists of four components: (1) hazard identification, (2) hazard characterisation, (3) exposure assessment, and (4) risk characterisation.

The rules of procedure however also provide that "other legitimate factors relevant for the health protection and fair trade 
practices may be identified in the risk management process and risk managers should indicate how these factors affect the selection of risk management options and the development of standards, guidelines and related texts. Only those factors which can be accepted on a world-wide basis (or regional for regional standards) should be taken into account in the framework of Codex. Consideration of other factors in the development of risk management recommendations should be made explicit by being clearly documented, including the rationale for their inclusion on a case-by-case basis. Risk management should take into account economic consequences and the feasibility of risk management options. Concerns related to economic interest and trade issues in general should be substantiated by quantifiable data" (CAC, 2005).

In the end, therefore the conception of the Risk Analysis procedure under the CAC shares the same basic features as that of the SAFE FOODS project. There are no procedural restrictions comparably to the limitations of the scope of activities of EFSA to restrict the scope of assessment by expert committees too narrowly. SAFE FOODS recommendations on the formalisation of social and economic assessments pertaining also to "other legitimate factors" (see for example Traill \& König, this issue) are deemed compatible and deserve consideration in the context of implementation of the CAC procedures for improved transparency of the process.

However, without more detailed guidance at the CAC level on which and how "other legitimate factors" should be assessed and by whom, practitioners remain at a loss on how to approach this potentially thorny issues that can be associated with assessing differential distributions of risks, costs, and benefits of new food technologies and associated risk management measures (see also Traill \& König, this issue).

\subsection{Current practice in standard setting}

Framing and evaluation: under the CAC, the risk assessment is usually conducted by scientific expert advisory panels. These are the JECFA and the JMPR. The non-governmental organisation Consumers International, which represents all of its world-wide national member organisations at the CAC, participates in meetings on risk management issues by officials and as an observer in some of the expert group meetings.

Assessing uncertainties: wider adoption of the NUSAP method, recommended by SAFE FOODS (see Section 2), and where available data allows probabilistic modelling methods, is compatible with current practice of the CAC scientific advisory panels and committees.

The scope of assessment: the SAFE FOODS recommendations also keep the focus of the assessment on health impacts. However, one difference is that risks and benefits to human health should be considered, where the choice of regulatory measure may significantly impact both. This definition of health assessment is broader and may not be incompatible with that of Codex. This may be an issue that would need to be decided in judicial review by the Appellate Body, largely based on resulting health benefits and not only on risks were to result in trade-discriminatory results.

Interestingly, on the assessment of economic and social impacts, the CAC Commission is less restrictive in the possible terms of reference for scientific experts charged with assessment than the EU for EFSA. If requested by the Codex Committee on Food Additives and Contaminants, the JECFA assess the potential impact of different agricultural production practices on contaminant levels in foods to the extent that scientific data are available to support such assessments. This assessment can be taken into account when considering risk management options and for proposing codes of practice. This however is one of very few statements on how information in the assessment should be drawn on when deciding on risk management options. In contrast, the scientific panels of EFSA would not be allowed to consider factors that may weigh into decision-making such as "the impact [of alternative regulatory measures] on agricultural production" as are scientific committees under the CAC, if they are given the remit (see Section 2)

The SAFE FOODS Risk Analysis Framework recommends extending the scope of assessment where necessary to include economic and/or social impacts, however adapted to the current EU legislative framework in recommending that such assessments would need to be conducted under the auspices of DG SANCO. This is considered compatible with current practice under CAC, which does not shun away from assessing these factors. However, under CAC as in the EU, there is little guidance on what social and economic impacts can be considered, and whether provisions in the CAC procedural manual suffice to legitimize reference to such other factors in Member State decisions on standards and regulatory measures at all to ensure that these are compliant with the SPS Agreement (Alemanno, 2007a, 2007b). One key issue that remains unclear is what type of impacts is considered relevant on a world-wide basis.

It seems, however, that, at large, SAFE FOODS recommendations are compatible with CAC rules of procedure. The main questions pertain to the scope and content of the assessment of economic and social impacts of alternative regulatory measures. One approach to tackling this question may be to gain greater clarity through further research on which of these aspects have relevance on a world-wide basis - can categories of impacts be developed using such criteria as geographic reach or regional confines of impacts? This area is recommended for further research.

\section{Conclusions: towards greater public accountability and improved resource allocation}

A first mapping suggests that SAFE FOODS recommendations of instituting a risk analysis procedure that formalises framing and evaluation activities, and that foresees the possibility to expand the scope of the assessment to include social and economic impacts are compatible with current principles, policies, laws, rules for procedure, and institutional set-ups of the food safety governance systems of the EU and the WTO.

It seems to be, however, true that practices to enhance the transparency on the role of "other legitimate factors" in decisionmaking processes would need to be clarified and refined through judicial review. The main aspect that will remain to be clarified are boundaries between impacts considered legitimate and relevant on an EU- or world-wide basis and impacts that are considered too regional or local and that are seen to negatively impact trade. But in the interest of achieving greater transparency and bringing decisions closer to citizens in the information age, and creating greater accountability, opening up the black box of regulatory objectives, and tensions between health and environmental objectives, trade objectives, and fostering active industries, by placing it under judicial review may well be warranted. In particular in the WTO food safety governance system, where the Appellate Body now increasingly starts to acknowledge and has inferred in past rulings that it recognizes often science alone is not sufficient to for choice of regulatory action (Alemanno, 2007b), it will be interesting to see more case law. These questions may also open up new fields of research on attempts to better define types of impacts according to their geographic reach or regional or local confines.

Another larger issue that is at question here is the actual role of the WTO. The current focus on science under the WTO can be seen to give rise to a more adversarial system, in which real reasons for choice of regulatory measures often remain hidden, making the role of the judges very difficult in having to arbitrate on scientific evidence and its adequacy (or sufficient evidence). Perhaps a WTO system that is acknowledged to be a negotiating ground for 
countries on trade, rather than a dispute settlement body, and in which there are clear guidelines on what types of and how other legitimate factors may be considered would provide more fruitful grounds and more constructive approach for trade agreements. The SAFE FOODS recommendations could be seen as applicable to the conception of such an improved system at the international level. Further more in-depth research on this question is recommended.

\section{Acknowledgements}

Alberto Alemanno carefully reviewed the document several times and made helpful suggestions from an insider perspective as lawyer in the court of justice. Conversations with Herwig Hofmann inspired a systematic approach to the comparative legal analysis and its presentation. Financial support from the SAFE FOODS project was the basis for the realisation of this paper.

\section{References}

Alemanno, A. (2006). Food safety and the single European market. In C. Ansell \& D Vogel (Eds.), What's the beef? The contested governance of European food safety (pp. 237-258). Cambridge and London: MIT Press.

Alemanno, A. (2007a). EU risk regulation and science: The role of experts in decision-making and judicial review. In E. Vos (Ed.) European risk governance, it science, its inclusiveness and its effectiveness, CONNEX report series no. 6 (pp. 3787). Mannheim: CONNEX Network, University of Mannheim. <http:// www.clingendael.nl/cesp/staff/aschout/20080200_cesp_chapter_schout_connex. pdf\#page $=45>$

Alemanno, A. (2007b). Trade in food-regulatory and judicial approaches in the EC and the WTO. London: Cameron May.

Alemanno, A. (2009). The better regulation initiative at the judicial gate: A Trojan horse within the commission's walls or the way forward? European Law Journal, 15(3), 382-400. doi:10.1111/j.1468-0386.2009.00467.x.

Arrow, K. J., Cropper, M. L., Eads, G. C., Hahn, R. W., Lave, L. B., Noll, R. G., et al. (1996). Is there a role for benefit-cost analysis in environmental, health, and safety regulation? Science, 272(5259), 221-222. doi:10.1126/science.272.5259. 221.

Boon, P. E., Svensson, K., Moussavian, S., van der Voet, H., Petersen, A., Ruprich, J., et al. (2009). Probabilistic acute dietary exposure assessments to captan and tolylfluanid using several European food consumption and pesticide concentration databases. Food and Chemical Toxicology, 47(12), 2890-2898. doi:10.1016/j.fct.2009.01.040.

Bos, P. M. J., Boon, P. E., van der Voet, H., Janer, G., Piersma, A. H., Brüschweiler, B. J., et al. (2009). A semi-quantitative model for risk appreciation and risk weighing. Food and Chemical Toxicology, 47(12), 2941-2950. doi:10.1016/j.fct.2009.03.009.

Bosgra, S., van der Voet, H., Boon, P. E., \& Slob, W. (2009). An integrated probabilistic framework for cumulative risk assessment of common mechanism chemicals in food: An example with organophosphorus pesticides. Regulatory Toxicology and Pharmacology, 54(2), 124-133. doi:10.1016/j.yrtph.2009.03.004.

CAC (2005). Procedural manual (14th ed.). Rome: Codex Alimentarius Commission, Joint FAO/WHO Food Standards Program, Food and Agriculture Organisation of the United Nations. <http://www.codexalimentarius.net/web/procedural manual.jsp>.

Cope, S., Frewer, L. J., Renn, O., \& Dreyer, M. (2010). Potential methods and approaches to assess social impacts associated with food safety issues. Food Control, 21(12), 1629-1637.

Craig, P., \& De Burca, G. (2003). EU law: Text, cases, and materials. New York and Oxford: Oxford University Press.

Davies, H. (2010). A role for "omics" technologies in food safety assessment. Food Control, 21(12), 1601-1610.

Dreyer, M., Renn, O., Ely, A., Stirling, A., Vos, E., \& Wendler, F. (2008). A genera framework for the precautionary and inclusive governance of food safety. Final report of the EU-project SAFE FOODS, work package 5, deliverable 5.8. Stuttgart: DIALOGIK. <http://www.dialogik-expert.de/en/forschung/A\%20General\%20 Framework\%20for\%20the\%20Precautionary\%20and\%20Inclusive\%20Governance\% 20of\%20Food\% 20Safety.pdf>.

Dreyer, M., Renn, O., Cope, S., \& Frewer, L. J. (2010). Including social impact assessment in food safety governance. Food Control, 21(12), 1620-1628.

Dreyer, M., \& Renn, O. (2006). The scientific approach to comparing institutional rearrangements in European food safety governance. In E. Vos \& F. Wendler (Eds.). Food safety regulation in Europe: A comparative institutional analysis (Ius Commune Europaeum, Vol. 62, pp. 1-8). Antwerp: Intersentia.

EU (2001). Regulation (EC) 1049/2001 of the EU Parliament and of the Council of 30 May 2001 regarding public access to European Parliament, Council and Commission documents. Official Journal of the European Communities, L145, 43-48. <http://eur-lex.europa.eu/LexUriServ/LexUriServ.do?uri=OJ:L:2001:145: 0043:0048:EN:PDF>.

EU (2002). Regulation (EC) No. 178/2002 of the European Parliament and of the Council of 28 January 2002 laying down the general principles and requirements of food law, establishing the European Food Safety Authority and laying down procedures in matters of food safety. Official Journal of the European Communities, L31, 1-24. <http://eur-lex.europa.eu/LexUriServ/ LexUriServ.do?uri=OJ:L:2002:031:0001:0024:EN:PDF>

EU (2003). Regulation (EC) No. 1829/2003 of the European Parliament and of the Council of 22 September 2003 on genetically modified food and feed. Official Journal of the European Communities, L268, 1-23. http://eur-lex.europa.eu/ LexUriServ/LexUriServ.do?uri=OJ:L:2003:268:0001:0023:EN:PDF.

EU (2006). Regulation (EC) No. 1907/2006 of the European Parliament and of the Council of 18 December 2006 concerning the Registration, Evaluation, Authorisation and Restriction of Chemicals (REACH), establishing a European Chemicals Agency, amending Directive 1999/45/EC and repealing Council Regulation (EEC) No. 793/93 and Commission Regulation (EC) No. 1488/94 as well as Council Directive 76/769/EEC and Commission Directives 91/155/EEC, 93/ 67/EEC, 93/105/EC and 2000/21/EC. Official Journal of the European Communities, L396, 1-849. <http://eur-lex.europa.eu/LexUriServ/LexUriServ.do?uri=OJ:L: 2006:396:0001:0849:EN:PDF>

European Commission (1997a). Communication of the European Commission: Consumer Health and Safety COM (97) 183fin. Brussels: European Commission. <http://ec.europa.eu/food/fs/sc/comec1en.pdf>.

European Commission (1997b). Green paper on the general principles of food law in the European Union, COM (97) 176, bulletin EU 4-1997, internal market (10/18). Brussels: European Commission. <http://europa.eu/bulletin/en/9704/p103042. htm>.

European Commission (2000a). Communication from the Commission on the precautionary principle COM (2000) 1. Brussels: European Commission. <http:// ec.europa.eu/dgs/health_consumer/library/pub/pub07_en.pdf>.

European Commission (2000b). Opinion of the Scientific Steering Committee on harmonisation of risk assessment procedures (adopted on 26-27 October 2000). Brussels: Scientific Steering Committee, European Commission. <http:// ec.europa.eu/food/fs/sc/ssc/out82_en.html>.

European Commission (2002a). Communication from the Commission: Towards a reinforced culture of consultation and dialogue - general principles and minimum standards for consultation of interested parties by the Commission, COM (2002) 704 final. Brussels: European Commission. <http://eur-lex.europa.eu/LexUriServ/ LexUriServ.do? uri=COM:2002:0704:FIN:EN:PDF>

European Commission (2002b). Commission Communication on the operating framework for the European regulatory agencies, COM (2002) 718. Brussels: European Commission. <http://ec.europa.eu/governance/docs/comm_agence_ en.pdf $>$.

European Commission (2005). Impact assessment guidelines, SEC(2005) 791. Brussels: European Commission. <http://ec.europa.eu/enterprise/regulation/better regulation/impact_assessment/docs/sec_2005_791_guidelines_annexes.pdf>.

European Commission (2007). "Healthy Democracy", conclusions and actions following the DG SANCO 2006 Peer review group on stakeholder involvement. Brussels: Directorate-General for Health and Consumers, European Commission. <http://ec.europa.eu/health/ph_overview/health_forum/docs/ ev_20070601_rd08_en.pdf>.

FAO/WHO (1995). Risk analysis in food safety standard issues. Report of the Joint FAO/ WHO Expert Consultation, Geneva, Switzerland, 13-17 March, 1995. Rome: Food and Agriculture Organization. <http://www.who.int/foodsafety/publications/ micro/en/march1995.pdf>.

FAO/WHO (1997). Risk management and food safety, report of a Joint FAO/WHO Consultation, Rome, Italy, 27-31 January 1997. Rome: Food and Agriculture Organization. <ftp://ftp.fao.org/docrep/fao/w4982e/w4982e00.pdf>.

FAO/WHO (1999). The application of risk communication to food standards and safety matters. Report of a Joint FAO/WHO Expert Consultation, Rome, 2-6 February 1998 (FAO Food and Nutrition Paper 70). Rome: Food and Agricultural Organisation of the United Nations. <http://www.fao.org/DOCREP/005/X1271E/X1271E00. htm>.

Fisher, E. (2007). Risk regulation and administrative constitutionalism. Oxford and Portland: Hart Publishing.

Funtowicz, S. O., \& Ravetz, J. R. (1990). Uncertainty and quality in science for policy. Dordrecht: Kluwer.

Funtowicz, S. O., \& Ravetz, J. R. (1992). Three types of risk assessment and the emergence of post-normal science. In S. Krimsky \& D. Golding (Eds.), Social theories of risk (pp. 251-274). Westport, CT: Praeger.

Funtowicz, S. O., \& Ravetz, J. R. (1993). Science for the post-normal age. Futures, 25(7), 739-755. doi:10.1016/0016-3287(93)90022-L.

Gabbi, S. (2007). The interaction between risk assessors and risk managers. European food and feed law review(3), 126-135.

Gottweis, H. (2008). Participation and the new governance of life. Biosocieties, 3(3), 265-286. doi:10.1017/S1745855208006194 (Corrigendum in BioSocieties, 3(4), 457. doi: $10.1017 /$ S1745855208006388).

Guston, D. H. (2000). Between Politics and Science: Assuring the integrity and productivity of research. New York: Cambridge University Press.

Hofmann, H. C. H. (2008). Mapping the European administrative space. West European Politics, 31(4), 662-676. doi:10.1080/01402380801905918.

Hofmann, H. C. H., \& Tuerk, A. H. (2006). EU administrative governance. Cheltenham: Edward Elgar Publishing Limited.

Jasanoff, S. (1987). Contested boundaries in policy-relevant science. Social Studies of Science, 17(2), 195-230. doi:10.1177/030631287017002001.

Jasanoff, S. (1995). Science at the bar: Law, science, and technology in America. Cambridge, MA: Harvard University Press.

Jasanoff, S. (1997). Civilization and madness: The great BSE scare of 1996. Public Understanding of Science, 6, 221-232. doi:10.1088/0963-6625/6/3/002. 
Jasanoff, S. (2003). Technologies of humility: Citizen participation in governing science. Minerva, 41(3), 223-244. doi:10.1023/A:1025557512320.

Jasanoff, S. (2006). Transparency in public science: reasons, purposes, limits. Law and Contemporary Problems, 69(21), 21-45.

Kasemir, B., Jäger, J., Jaeger, C. C., \& Gardner, M. T. (2003). Public participation in sustainability science. A handbook. Cambridge: Cambridge University Press.

König, A. (2002). Negotiating the precautionary principle: Regulatory and institutional roots of divergent US and EU positions. International Journal of Biotechnology, 4(1), 61-80. doi:10.1504/IJBT.2002.000180.

König, A. (2007a). Towards safer foods and more democratic decisions: Is this a contradictory goal? OCL Oleagineux, Corps Gras Lipides, 14(2), 92-99. doi:10.1684/ocl.2007.0130. <http://www.john-libbey-eurotext.fr/e-docs/00/ 04/33/F2/vers_alt/VersionPDF.pdf>.

König, A. (2007b). Democratizing decision-making on food safety in the EU: Closing gaps between principles of governance and practice. Minerva, 45(3), 275-294. doi:10.1007/s11024-007-9044-0.

König, A., Kuiper, H. A., Marvin, H. J. P., Boon, P. E., Busk, L., Cnudde, F. C., et al. (2010). The SAFE FOODS framework for improved risk analysis of foods. Food Control, 21(12), 1566-1587.

König, A., \& Jasanoff, S. (2002). The credibility of expert advice for regulatory decisionmaking in the US and EU. Working paper RPP-2002-07. Cambridge, MA: Mossavar Rahmani Center for Business and Government, John F. Kennedy School of Government, Harvard University.

Kuiper, H. A., \& Davies, H. V. (2010). The SAFE FOODS risk analysis framework suitable for GMOs? A case study. Food Control, 21(12), 1662-1676.

Müller, A. K., Bosgra, S., Boon, P. E., van der Voet, H., Nielsen, E., \& Ladefoged, 0. (2009). Probabilistic cumulative risk assessment of anti-androgenic pesticides in food. Food and Chemical Toxicology, 47(12), 2951-2962. doi:10.1016/ j.fct.2009.07.039.

Muri, S. D., van der Voet, H., Boon, P. E., van Klaveren, J. D., \& Brüschweiler, B. J. (2009). Comparison of human health risks resulting from exposure to fungicides and mycotoxins via food. Food and Chemical Toxicology, 47(12), 2963-2974. doi:10.1016/j.fct.2009.03.035.

National Research Council (1994). Science and judgment in risk assessment. Washington, DC: National Academy Press. <http://books.nap.edu/openbook. php?isbn=030904894X>

Ravetz, J. R. (1999). Post-normal science (special issue). Futures, 31(7), 641-757.

Renn, O. (2007). Components of the risk governance framework. In F. Bouder, D. Slavin, \& R. Lofstedt (Eds.), The tolerability of risk. A new framework for risk management (Earthscan risk in society series) (pp. 7-83). London: Earthscan. <http://www.earthscan.co.uk/Portals/0/Files/Sample\%20Chapters/ 9781844073986.pdf>.

Rudloff, B., \& Simons, J. (2007). European governance of food safety. In H. C. H. Hofmann \& A. Türk (Eds.), EU administrative governance (pp. 146-184). Cheltenham: Edward Elgar.

SAFE FOODS (2005). Workpackage 6: Design of a new integrated risk analysis approach for foods. Wageningen: SAFE FOODS Project, c/o RIKILT - Institute of Food
Safety, Wageningen University and Research Centre. <http://www.safefoods.nl/ Paginas/SAFE\%20FOODS\%20overview/Workpackage\%206\%20overview.aspx>.

SAFE FOODS (2007). SAFE FOODS second stakeholder consultation successful. Wageningen: SAFE FOODS Project, c/o RIKILT - Institute of Food Safety Wageningen University and Research Centre. <http://www.safefoods.nl/Lists News/DispForm.aspx?ID=46\&Source=http\%3A\%2F\%2Fwww\%2Esafefoods\%2Enl \%2FLists\%2FNews\%2FAllItems\%2Easpx>.

Smith, M. (2002). Food safety in Europe (FOSIE): Risk assessment, of chemicals in food and diet: Overall introduction. Food and Chemical Toxicology, 40(2/3), 141-144. doi:10.1016/S0278-6915(01)00112-0.

Thompson, K. M., \& Graham, J. D. (1996). Going beyond the single number: Using probabilistic risk assessment to improve risk management. Human and Ecological Risk Assessment, 2(4), 1008-1034. doi:10.1080/10807039609383660.

Toeller, A. E., \& Hofmann, H. C. H. (2000). Democracy and the reform of comitology In M. Andenas \& A. Turk (Eds.), Delegated legislation and the role of committees in the EC (pp. 25-50). London: Kluwer Law International.

Traill, W. B., \& König, A. (2010). Economic assessment of food safety standards: Costs and benefits of alternative approaches. Food Control, 21(12), 1611-1619.

Van der Voet, $\mathrm{H}$, van der Heijden, G. W. A. M., Bos, P. M. J., Bosgra, S., Boon, P. E. Muri, S. D., et al. (2009). A model for probabilistic health impact assessment of exposure to food chemicals. Food and Chemical Toxicology, 47(12), 2926-2940. doi:10.1016/j.fct.2008.12.027.

Van der Voet, H., \& Slob, W. (2007). Integration of probabilistic exposure assessment and probabilistic hazard characterization. Risk Analysis, 27(2), 351-371. doi:10.1111/j.1539-6924.2007.00887.x.

Vos, E. (2000). Reforming the European Commission: What role to play for EU agencies? Common Market Law Review, 37(5), 1113-1134

Vos, E., \& Wendler, F. (2006). Food safety regulation in Europe: A comparative institutional analysis (Ius commune Europaeum Series, Vol. 62). Antwerp: Intersentia.

Wardecker, J. A., de Boer, J., Kolkman, M. J., van der Sluijs, J. P., Buchanan, K. S., de Jong A., et al. (2009). Tool catalogue frame-based information tools. Utrecht: Copernikus Institute, Department of Science, Technology, and Society, Utrecht University. $<$ http://www.nusap.net/article.php?sid=44\&mode=thread\&order=0>.

Wentholt, M. T. A., Rowe, G., König, A., Marvin, H. J. P., \& Frewer, L. J. (2009). The views of key stakeholders on an evolving food risk governance framework: Results from a Delphi study. Food Policy., 34, 539-545. doi:10.1016 j.foodpol.2009.06.002.

Wynne, B. (1985). Uncertainty, technical and social. In H. Brooks \& C. L. Cooper (Eds.), Science for public policy (pp. 95-115). Oxford: Pergamon Press.

Wynne, B. (1996). Misunderstood misunderstanding: Social identities and public uptake of science. In A. Irwin \& B. Wynne (Eds.), Misunderstanding Science? The Public Reconstruction of Science and Technology (pp. 19-46). Cambridge: Cambridge University Press.

Wynne, B. (2003). Seasick on the third wave? Subverting the hegemony of proportionalism: Response to Collins and Evans (2002). Social Studies of Science, 33(3), 401-417. doi:10.1177/03063127030333005. 